\title{
The Future of Cognitive Behavioral Therapy
}

\author{
Stefan G. Hofmann ${ }^{1,2}$ (D) \\ Published online: 17 May 2021 \\ (c) The Author(s), under exclusive licence to Springer Science+Business Media, LLC, part of Springer Nature 2021
}

\begin{abstract}
Aaron T. Beck, the founder of this journal and the father of cognitive behavioral therapy (CBT), is turning 100 on June 18th, 2021. This special issue on the Future of CBT provides a glimpse into the next frontier of CBT research and practice. Some of the leading CBT scholars and researchers, including Dr. Beck himself, will explore new CBT approaches for schizophrenia, OCD, depression, and envy.
\end{abstract}

Keywords Cognitive behavioral therapy $\cdot$ Cognitive therapy $\cdot$ Behavioral therapy $\cdot$ Psychotherapy

Cognitive behavioral therapy (CBT) is arguably one of the most important advances in the treatment of psychopathology in the last 50 years. This is not the self-serving exaggeration of an editor promoting his own journal, but it was the judgment of the Lasker jury when announcing the 2006 Albert Lasker Award for Clinical Medical Research to Dr. Aaron T. Beck. The Lasker Award is the most prestigious medical prize, often bestowed to individuals who subsequently win the Nobel Prize.

This description of CBT by the Lasker jury is well-justified. The evidence-base of CBT is staggering and overwhelmingly strong (David et al., 2018). For example, almost a decade ago, some of my students and I reviewed the literature on the efficacy of CBT for mental health problems in this very journal (Hofmann et al., 2012). The evidence today has undoubtedly grown further since then. Back in 2012, we identified no fewer than 269 meta-analytic studies. We found strong evidence that CBT is effective for a huge range of health problems. The list of problems that responds well to CBT includes substance use disorder, schizophrenia and other psychotic disorders, depression and dysthymia, bipolar disorder, anxiety disorders, somatoform disorders, eating disorders, insomnia, personality disorders, anger and

Stefan G. Hofmann

shofmann@bu.edu

1 Department of Psychological and Brain Sciences, Boston University, 900 Commonwealth Avenue, Boston, MA 02215 , USA

2 Department of Psychology, Philipps-University Marburg, Marburg, Germany aggression, criminal behaviors, general stress, distress due to general medical conditions, chronic pain and fatigue, and distress related to pregnancy complications and female hormonal conditions. Some of these reviews also examined the efficacy of CBT for problems in children and elderly adults. Overall, we found the strongest support of CBT for anxiety disorders, somatoform disorders, bulimia, anger control problems, and general stress. Although clearly efficacious, there is still room for improvement, because a substantial number of patients still remain symptomatic even after a full course of CBT. Also, except for children and elderly populations, few (if any) meta-analytic studies of CBT have reported on specific subgroups, such as ethnic minorities and low income samples. Thus, although CBT can still be improved and expanded, it clearly paves the way for the future given its remarkable success.

It seems redundant to explain the basic idea of CBT to the readership of this journal. It would also be impossible and inaccurate to reduce CBT to a single approach or strategy. Rather, CBT has evolved to include a range of evidencebased psychological procedures targeting a wide range of mental health problems (Beck, 2019). Thus, it is much more accurate to view CBT as a family of interventions that share a number of key treatment components and a similar overall general structure and approach to mental health problems. CBT is a client-centered and problem-focused approach that is based on the notion that behavioral and emotional responses are strongly moderated and influenced by cognitions and the perception of events. The word cognitive in CBT implies that treatment focuses a great deal on cognitive processes. However, therapy is not limited to cognitive 
modification. Effective CBT has to target all aspects of human suffering, including cognitions, emotional experience, and behavior. The general approach is based on the here and now, engaging the client in a collaborative relationship and as an active participant to find concrete solutions to mental health problems.

Today, the core idea of CBT, that cognitive processes causally and bi-directionally influence emotions and behavior, seems to be a truism. But this was a revolutionary approach only a few decades ago, when psychotherapy was still firmly rooted in Freudian thinking, which gave prominence to past experiences and unresolved unconscious processes. When CBT was introduced in the 1950s, it started nothing short of a paradigm shift in psychotherapy research and practice. Dr. Beck, the father of this paradigmatic shift, is turning 100 on July 18th, 2021. He was also founding editor of this very journal, Cognitive Therapy and Research, which has become the flagship publication for CBT. This special issue commemorates this event. Dr. Beck's contributions and impact are too wide, too broad, too deep, and too significant to do justice with a special issue. Instead, his birthday gives us time to reflect and to look ahead. I asked some speakers from previous meetings of the Beck Summit, a gathering of scholars, researchers and clinicians discussing the latest research in CBT, to share some of their thoughts. Dr. Beck was so kind and contributed an article describing some of his own current work, including articles on his Theory of Modes. Other contributions examine new perspectives in CBT for schizophrenia, depression, envy, OCD, and CBT in adolescents. The future of CBT is bright and clear. CBT has made and will continue to make this world a better place by relieving suffering and improving mental health. Thank you, Dr. Beck. Happy 100th birthday, Tim!

\section{References}

Beck, A. T. (2019). A 60-year evolution of cognitive theory and therapy. Perspectives on Psychological Science, 14, 16-20. https:// doi.org/10.1177/1745691618804187

David, D., Cristea, I., \& Hofmann, S. G. (2018). Why cognitive behavioral therapy is the current gold standard of psychotherapy. Frontiers in Psychiatry, 9, 4. https://doi.org/10.3389/fpsyt.2018.00004

Hofmann, S. G., Asnaani, A., Vonk, J. J., Sawyer, A. T., \& Fang, A. (2012). The efficacy of cognitive behavioral therapy: A review of meta-analyses. Cognitive Therapy and Research, 36, 427-440. https://doi.org/10.1007/s10608-012-9476-1

Publisher's Note Springer Nature remains neutral with regard to jurisdictional claims in published maps and institutional affiliations. 